\title{
EL ASENTAMIENTO \\ ORIENTALIZANTE E IBÉRICO ANTIGUO DE "LA RÁBITA", GUARDAMAR DEL SEGURA (ALICANTE). AVANCE DE LAS EXCAVACIONES 1996-1998
}

\author{
L'ÉTABLISSEMENT ORIENTALISANT \\ ET IBÉRIQUE ANCIEN DE "LA RÁBITA", \\ GUARDAMAR DEL SEGURA (ALICANTE, \\ ESPAGNE). CAMPAGNES DE FOUILLES, \\ 1996-1998
}

\author{
RAFAEL AZUAR (*) \\ PIERRE ROUILLARD $(* *)$ \\ ERIC GAILLEDRAT $(* * *)$ \\ PIERRE MORET $(* * * *)$ \\ FELICIANA SALA SELLES $(* * * * *)$ \\ ALAIN BADIE $(* * * * * *)$
}

\section{RESUMEN}

Al sur de la desembocadura del río Segura, la excavación de La Rábita califal ha revelado la existencia, en el mismo lugar, de un establecimiento de época Orientalizante/Protoibérica e Ibérica Antigua. El hábitat, cuya historia empieza probablemente a finales del siglo VIII o en torno al 700 a.C., en un momento que se puede fijar hacia el 600 a.C., fue rodeado de una potente muralla que incluye una superficie de 1,5 Ha. El asentamiento ha sido un lugar de intercambios intensos con el mundo orientalizante y fenicio-occidental. cial. Alicante

(*) Museo Arqueológico Provincial, Diputación Provin(*) CNRS, URA 1473, Universités de Paris I' et Paris X, Maison de l'Archéologie et de l'Ethnologie René Ginouvès, 21 Allée de l'Université. 92000 Nanterre. E. Mail: rouillard@ mae.uparis10.fr

(**) CNRS, UMR 154, CDAR, 390 Avenue de Pérols. 34970 Lattes. E. Mail: umrlat@cnrs-mop.fr

(****) CNRS, UMR 5608, UTAH, Maison de la Recherche, 5 Allée Antonio Machado, 31058 Toulouse, Cedex 01. E. Mail: moret@univ-tlse2.fr

$(* * * * *)$ Departamento de Arqueologia. Universidad de Alicante. San Vicente de Raspeig (Alicante). Correo electrónico: feliciana.sala@ua.s

$(* * * * *)$ CNRS, IRAA, Ancien Palais de l'Archevéché, 28 Place des Martyrs de la Résistance, 13100 Aix-en-Provence.

El artículo fue remitido en su versión final el 27-VII-98.

\section{RÉSUMÉ}

Au sud de l'embouchure du Segura, la fouille de La Rábita califale a révélé l'existence, au même emplacement, d'un établissement d'époque Orientalisante/Protoibérique et Ibérique Ancienne. L'habitat dont l'histoire commence probablement à la fin du VIIIe siècle ou aux environ de 700 avant J.-C. a été, à un moment que l'on peut situer autour de 600, entouré d'une puissante enceinte; il est alors vaste de 1,5 hectares. L'établissement a été un lieu d'échanges actifs avec le monde orientalisant et phénicien d'Occident.

Palabras claves: Edad del Hierro. Orientalizante. Ibérico Antiguo. Comercio. Fenicio. Fortificación. Adobe.

Mots clefs: Âge du fer. Orientalisant. Ibérique Ancien. Commerce. Phénicien. Fortification. Adobe.

\section{INTRODUCCIÓN, ESTADO DE LA CUESTIÓN}

\subsection{Situación geográfica}

A $28 \mathrm{~km}$ al sur de Alicante (Fig. 1), sobre el cauce derecho de la desembocadura del Segura, se en- 
cuentra la actual población de Guardamar del Segura. Hacia el oeste, el castillo ocupa un pequeño cerro predominante en cuya ladera este se situó el núcleo antiguo hasta el terremoto de 1829 , y hacia el este, bordeando el mar, se extiende una larga serie de dunas cuyos límites son al norte, La Marina, y al sur, Torrevieja. A un kilómetro al norte del actual centro urbano, en dirección hacia la desembocadura del Segura, se encuentra el lugar llamado "La Fonteta" (coordenadas UTM: $\mathrm{x}=706 ; \mathrm{y}=4219,95$ ) que desde finales del siglo XIX se conoce también como "La Mezquita". Desde 1897, se sabía la existencia de una "población antigua" enterrada bajo la arena de las dunas (Azuar et alii, 1989: 14). Pero hubo que esperar hasta las excavaciones de Rafael Azuar (1984-1992) para descubrir la continuada ocupación de este lugar: albergaba en realidad dos asentamientos distintos separados por un abandono de 1500 años, el primero un núcleo fortificado de época orientalizante, después una Rábita califal que se estableció en el cuarto noreste del recinto protohistórico.

\subsection{Antecedentes}

El descubrimiento de cerámica fenicia en el tapial de los muros de la Rábita medieval, desde 1984, constituyó el primer indicio de la existencia de una fase de ocupación protohistórica en el yacimiento de La Rábita.

En 1988, una prospección geofísica detecta una serie de anomalías, correspondientes a importantes estructuras construidas en piedra, rodeando el yacimiento medieval (1). La disposición de estas anomalías sugería la existencia de una muralla perimetral (Fig. 3), y de ahí que dos de ellas fueran elegidas por R. Azuar para efectuar sondeos.

En 1988, un primer sondeo de $10 \times 12 \mathrm{~m}$. fue realizado al suroeste del recinto, justo en el lugar donde la altura era menor (Fig. $3, n^{\circ} 3$ ), donde se puso al descubierto un tramo de muralla de varios metros de longitud. Su anchura es de $5 \mathrm{~m}$., y la altura del paramento externo es de 3,5 m. (Azuar $e t$ alii, 1989: 15). El aparejo de este paramento es tosco, realizado en piedras apenas escuadradas y trabadas con tierra (2).

(1) Informe de E. Cámara Moral y M.a del Carmen Hernández, Departamento de Geofísica de la Facultad de Ciencias Físicas de la Universidad Complutense de Madrid.

(2) Informe R. Azuar, M. Borrego y R. Saranova.

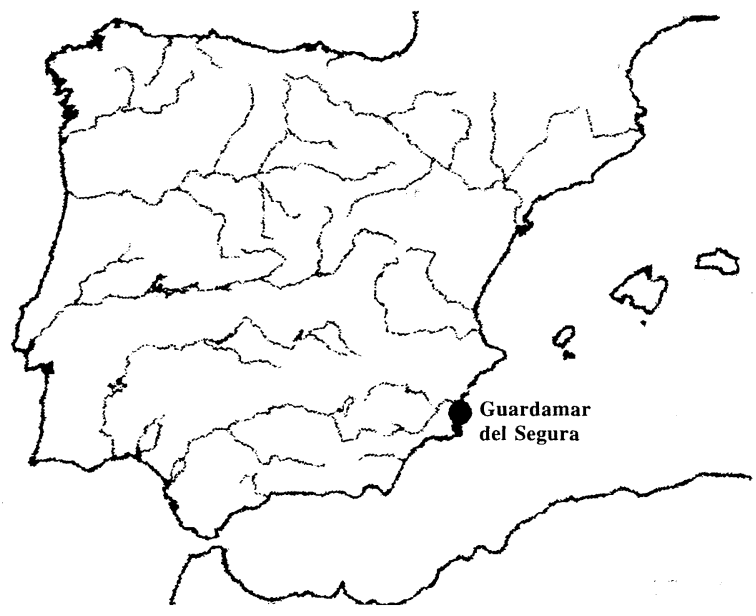

Fig. 1. Localización de La Rábita, Guardamar del Segura (Alicante) en la Península Ibérica.

En 1992, se planteó una excavación (3) más extensa hacia la mitad del frente oriental del recinto (Fig. $3, n^{\circ} 2$ ). El resultado fue el descubrimiento de un tramo de muralla con una longitud de $30 \mathrm{~m}$. y de dos construcciones adosadas al paramento interno. La base de la estratigrafía no se alcanzó en ningún caso, pero las tres intervenciones revelaron la existencia de estructuras arcaicas y permitieron formarse una idea de la amplitud y forma del yacimiento.

\section{MÉTODO Y OBJETIVOS}

El proyecto de excavación se inscribe en una reflexión global sobre los intercambios en la región sur-oriental a partir del final de la Edad del Bronce. Con anterioridad, las prospecciones en el Bajo Segura nos permitieron trazar las grandes líneas de la evolución del poblamiento desde el final de la Edad del Bronce hasta época islámica (Fig. 2). Posteriormente, la excavación del hábitat costero de La Picola (Santa Pola) muestra el comercio marítimo de este área entre mediados del siglo $\mathrm{V}$ y la mitad del siglo IV: al menos en este momento, Santa Pola era el puerto de Elche y un lugar privilegiado para los intercambios comerciales (4).

Para el período anterior, entre los siglos VIII/VII y finales del VI, el hábitat de La Rábita de Guardamar ejerce esta misma función (Fig. 2). Los yaci-

(3) Informe R. Azuar, I. Quiles y M.a T. Llopis.

(4) Publicación de conjunto (prospecciones en el Bajo Segura y excavación de La Picola, Santa Pola) en curso de realización. Sobre La Picola, se puede consultar los siguientes avances: Moret et alii, 1995 y 1996.

T. P., 55, n. ${ }^{\circ} 2,1998$ 


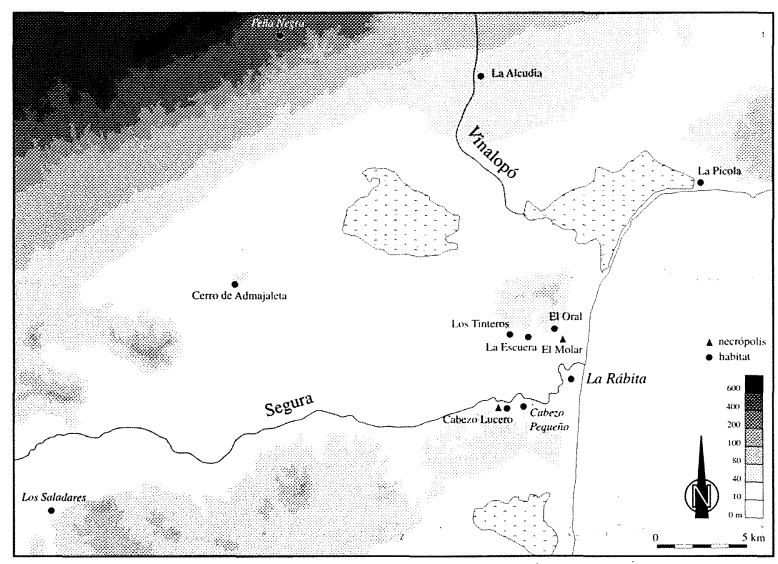

Fig. 2. El bajo Segura durante la Edad del Hierro. Los nombres de los yacimientos de época orientalizante están indicados en itálicas.

mientos del interior del sur de la provincia de Alicante, Los Saladares (Orihuela) (Arteaga y Serna, 1975 y 1980) y Peña Negra (Crevillente) (Gónzalez Prats, 1993a, b), por citar sólo los más importantes durante el periodo orientalizante, disponían aquí de un acceso al mar, como así indican los productos orientales (esencialmente fenicios) y orientalizantes (sobre todo de Andalucía) que se encuentran. Esta nueva etapa de nuestra reflexión se plantea cuando Rafael Azuar, conservador del Museo Arqueológico de Alicante, pide al equipo que acababa de realizar el estudio de Santa Pola codirigir la excavación de los niveles arcaicos de La Rábita. El trabajo empezó en junio de 1996 (5) con un equipo de arqueólogos, un arquitecto, un topógrafo y un geólogo (6).

La primera fase de nuestro proyecto de tres años, en el área abierta por los excavadores de 1992, te-

(5) El permiso de excavación de la Consellería de Cultura de la Generalitat Valenciana, con una duración de tres años, estipula que la excavación se desarrolle en el espacio abierto durante la campaña de 1992.

(6) Los arqueólogos son los firmantes de este texto; la planimetria general está a cargo de Alain Badie, arquitecto, ingeniero del CNRS (IRAA, Aix-en-Provence), y Pierre Duboeuf, ingeniero del CNRS (URA 1473, Paris). Los primeros estudios geológicos fueron realizados por Pascal Barrier, profesor de L'IGAL, Centre polytechnique Saint-Louis. Las excavaciones de 1996, 1997 y 1998 han sido subvencionadas por la Sous-direction des sciences sociales et humaines et de l'archéologie du Ministère des Affaires Etrangères, junto con la participacion de la Casa de Velázquez que ha incluido la excavación de Guardamar del Segura entre sus programas. Agradecemos asimismo a la Diputación Provincial y al Museo Arqueológico de Alicante la integración de este proyecto en su Plan de Recuperación e Intervención del Patrimonio Arqueológico. La colaboración del Ayuntamiento de Guardamar y de su alcalde, Francisco García Gómez, nos ha sido de gran ayuda, poniendo a nuestra disposición obreros y sus servicios técnicos. nía dos objetivos prioritarios: la realización de la planimetria general del yacimiento y la reanudación de los trabajos de campo con una excavación en extensión en el interior del hábitat (Lam. I) y un sondeo en el exterior de la cortina (7).

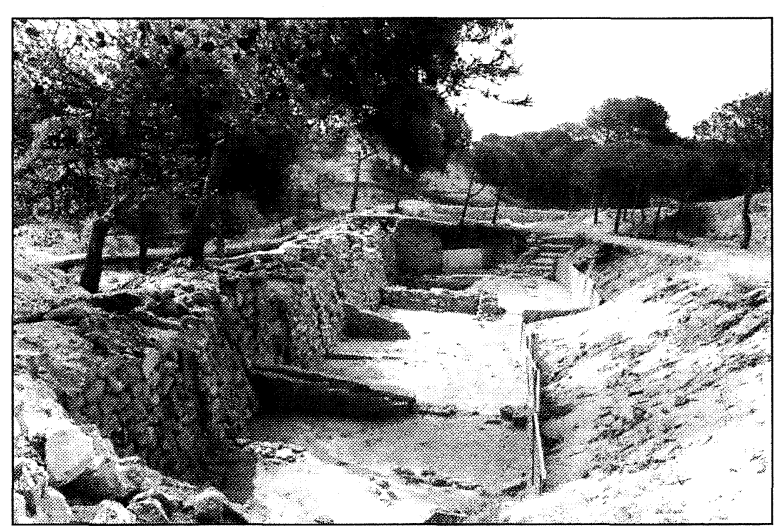

Lám. I. El yacimiento de La Rábita, Guardamar del Segura (Alicante), desde el noroeste.

\section{LAS ESTRUCTURAS}

\subsection{La muralla protoibérica}

La prospección geofísica de 1988 ha permitido comprobar la existencia de una muralla que se encuentra sepultada bajo la arena en la mayor parte de su recorrido. Su longitud total se estima entre 495 y $500 \mathrm{~m}$. (Fig. 3). Tiene una forma irregular alarga$\mathrm{da}$, con dos ángulos al noroeste y al sureste. Las cortinas son aproximadamente rectilíneas en los tramos del sur y el este, curvas en el norte y el oeste.

La superficie incluida es de una hectárea y media $\left(15.400 \mathrm{~m}^{2}\right)$. Nos encontramos, por tanto, ante un asentamiento de dimensiones más bien modestas; en la zona, su extensión es comparable a la de los poblados ibéricos de El Oral $(1,25 \mathrm{Ha}$.) y Cabezo Lucero (un poco mas de $1 \mathrm{Ha}$ ). Estamos lejos, pues, de las decenas de hectáreas estimadas para Peña Negra II y luego La Alcudia de Elche.

La excavación de 1992 exhumó un tramo de 30 m. de la cortina este. De 1996 a 1998, se ha descubierto su paramento interno en un frente de $25 \mathrm{~m}$. hasta los suelos del nivel protoibérico, y hasta el substrato en el extremo sur del sector A (Fig. 4 y 5). En el centro del área de excavación, en un sondeo exterior de 4 x 2,5 m. y otro interior de $3 \mathrm{x}$

(7) En 1996 y 1997, Alfredo González Prats y Antonio García Menárguez codirigen sendas campañas en el mismo yacimiento (esta vez denominado "La Fonteta"), al suroeste de nuestro sector de intervencion (Fig. $3, n^{\circ} 4$ ). 


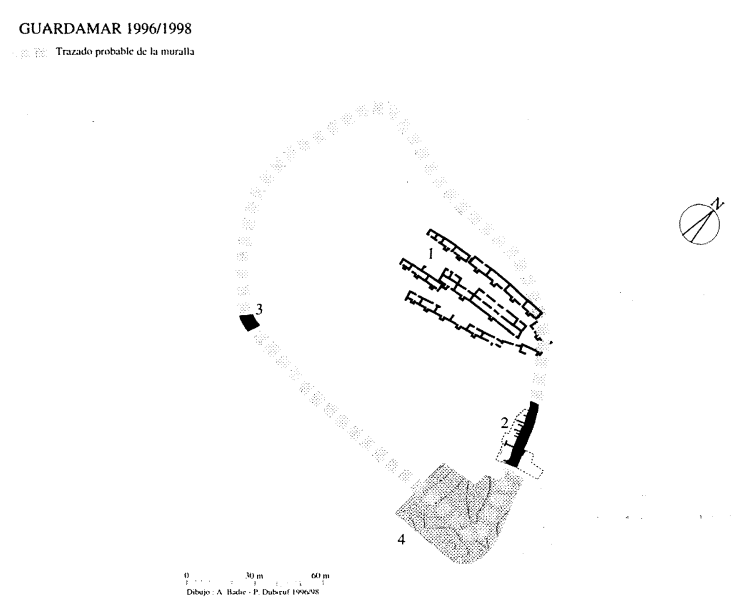

Fig. 3. El yacimiento arqueológico de La Rábita, Guardamar del Segura (Alicante). Trazado probable de la muralla definido a partir de la prospección geofísica efectuada en 1988: 1. Rábita califal; 2. Excavación 1992 y 1996/98 en la parte oriental del recinto protohistórico; 3. Sondeo 1988 en la parte suroeste de la muralla; 4. Localización de las zonas excavadas en 1996 y 1997 por A. González Prats.

$1,5 \mathrm{~m}$. se ha alcanzado la base de la muralla y los estratos subyacentes, mostrando así una estratigrafía casi completa de las estructuras internas de la muralla y de los niveles de ocupación infrapuestos (Fig. 5). Los datos obtenidos nos permiten conocer el sistema de construcción, por otro lado muy original, y fijar definitivamente su cronología.

Actualmente, la muralla conserva una altura que oscila entre 3 y $3,5 \mathrm{~m}$. Su anchura es de unos $4 \mathrm{~m}$. en las cotas superiores, mientras que en la base alcanza 5,80 m. en función del grado de inclinación de los paramentos $\left(71^{\circ}\right.$ para el exterior y $68^{\circ}$ para el interior). Lo conservado de la muralla corresponde a su basamento, casi enteramente construido en piedra. El material utilizado es una arenisca pliocénica local. Este mampuesto, trabado con tierra, forma un aparejo tosco que no era visible, como lo demuestra el hallazgo de fragmentos de un revestimiento de arcilla aparecidos en el sector C. Por encima de este basamento macizo, del que sólo debe faltar una pequeña parte de su remate, se elevaba una superestructura de adobes cuyos vestigios han sido encontrados in situ sobre el basamento, así como en las capas de destrucción que se extienden en la base de la muralla tanto en el interior como en el exterior.

La estructura interna de la muralla es particularmente compleja. Debemos distinguir dos sectores (Fig. 4 y 5). Al norte, el núcleo de la muralla está constituido por un muro de doble paramento de 2,60 a 2,80 m. de anchura con un relleno interno de piedras y tierra relativamente compacto (MR 35). Sendos paramentos de refuerzo se adosan al interior (MR 01) y al exterior (MR 51). Se trata, por tanto, de una muralla de paramentos múltiples, de un tipo bastante corriente en los inicios de la Edad del Hierro en España (Moret, 1996: 80-82). Lo que no es tan común es que el paramento interno del muro MR 35 alcanza su paramento externo con un quiebro en ángulo recto, formando una especie de caja muy alargada cuyo límite norte debe situarse fuera del área de excavación. Por otro lado, diversos muros de las viviendas hechos con adobes (MR 04, MR 05 y MR 23) penetran en todo el ancho del refuerzo interior, lo que demuestra que la construcción de estas viviendas y de la muralla fue simultánea.

Hacia el sur, en el espacio de 8,2 m. que separa el extremo sur de MR 35 y el extremo norte de MR 62 , la parte central de la muralla está constituida por dos estructuras paralelas: hacia el exterior, un muro de adobes (MR 37) (Lám. III), y hacia el interior un muro de piedra de factura tosca (MR 36). El muro de adobes -invisible antes de la destrucción de la muralla puesto que estaba tapado por paramentos en piedra- se conserva hasta una altura de $3,05 \mathrm{~m}$. Es más o menos vertical al oeste, en tanto que en el este presenta un talud similar al de MR 51. Su anchura es de $1,5 \mathrm{~m}$. en la base y de $0,8 \mathrm{~m}$. en el punto más alto. Los adobes de las dos hiladas de base presentan al oeste un saliente de $15 \mathrm{~cm}$. sobre el cual se apoyan los bloques de cimentación de MR 36. El hecho de que las piedras de MR 36 intesten con los adobes de MR 37 en toda la altura de la muralla demuestra que estas dos estructuras paralelas fueron construidas al mismo tiempo. No existe trinchera de fundación, de manera que los cuatro elementos constitutivos de la muralla (muros MR 51,37, 36 y 01 ) descansan directamente sobre los niveles antrópicos subyacentes previamente nivelados.

Se conservan 33 hiladas de adobes en el muro MR 37 (Lam. III). Su altura media es de 9,7 cm., sumando en ello el alto del adobe, que era de 8 a 9 $\mathrm{cm}$. más la llaga de arcilla. En el área del sondeo interior se han levantado en planta hasta 13 hiladas; así es como se han podido medir 101 adobes enteros y 91 incompletos. El aparejo es poco cuidado y las juntas pocas veces se presentan de manera alternante. Los adobes cuadrados y rectangulares se combinan en la misma hilada sin demasiada regularidad. Aunque las dimensiones de los adobes son muy variables, se puede distinguir un módulo cuadrado de 29 a $32 \mathrm{~cm}$ de lado (32\% de los adobes

T. P., 55, n. $^{\circ} 2,1998$ 

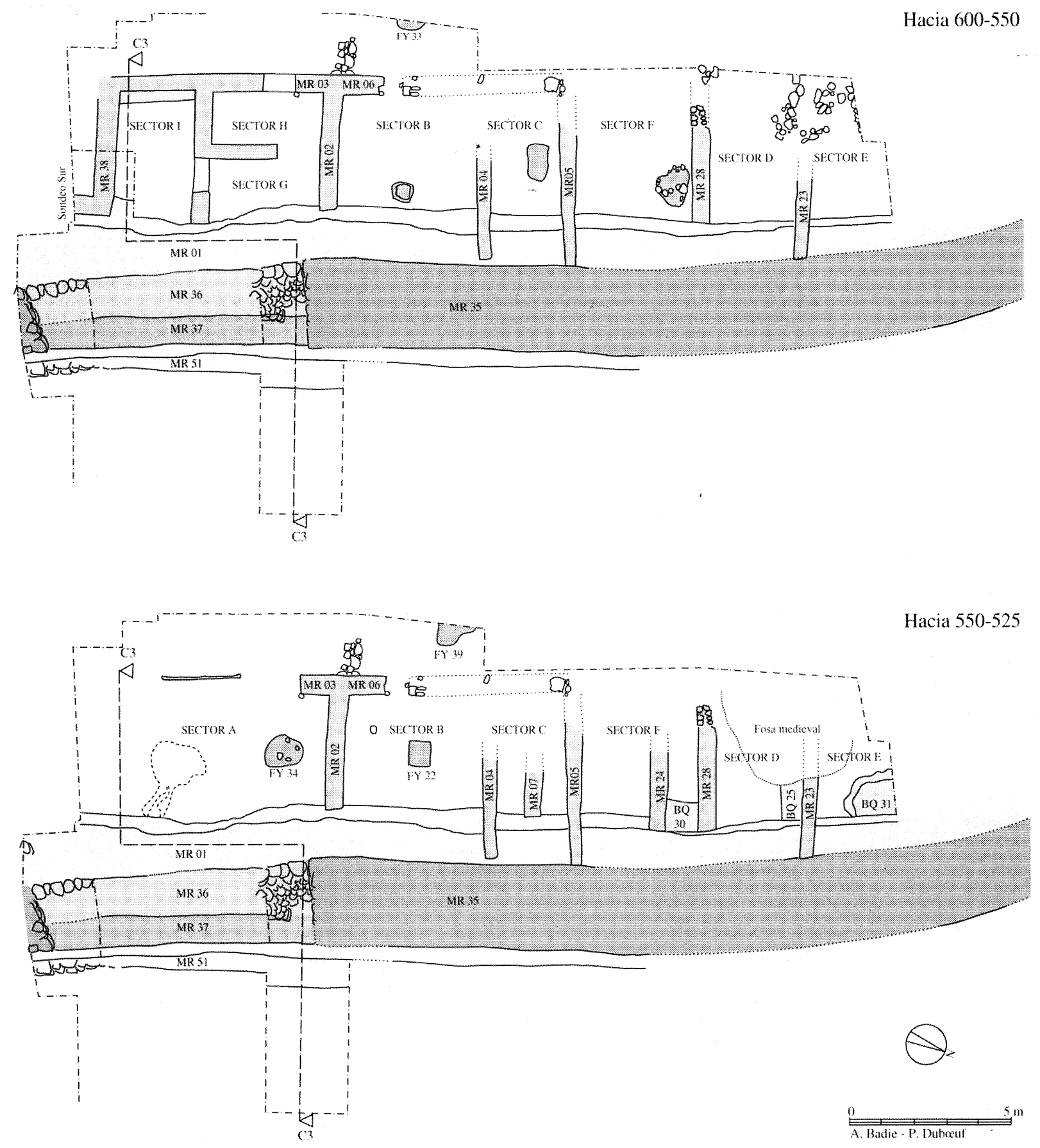

Fig. 4. Plano de la excavación de La Rábita, Guardamar del Segura (Alicante) después de la campaña de 1998.

completos) y, más dudosamente, varios módulos rectangulares: $34-37 \times 29-32 \mathrm{~cm}$. $(16 \%), 29-31 \mathrm{x}$ $22-25 \mathrm{~cm} .(11 \%)$ y $39-42$ x $29-33 \mathrm{~cm} .(7 \%)$.

La estratigrafía del corte C 3 (Fig. 5) nos ha proporcionado algunos datos cronológicos importantes para la reconstrucción de la secuencia.
1. En la base se encuentra un estrato formado por arena poco compacta alternando con bancos de calcarenita. Presenta una ligera pendiente hacia el este.

2. Una serie de capas de ocupación y destrucción con un espesor entre 0,8 y 1,2 m. precede a la construcción de la muralla. En el exterior, se trata 


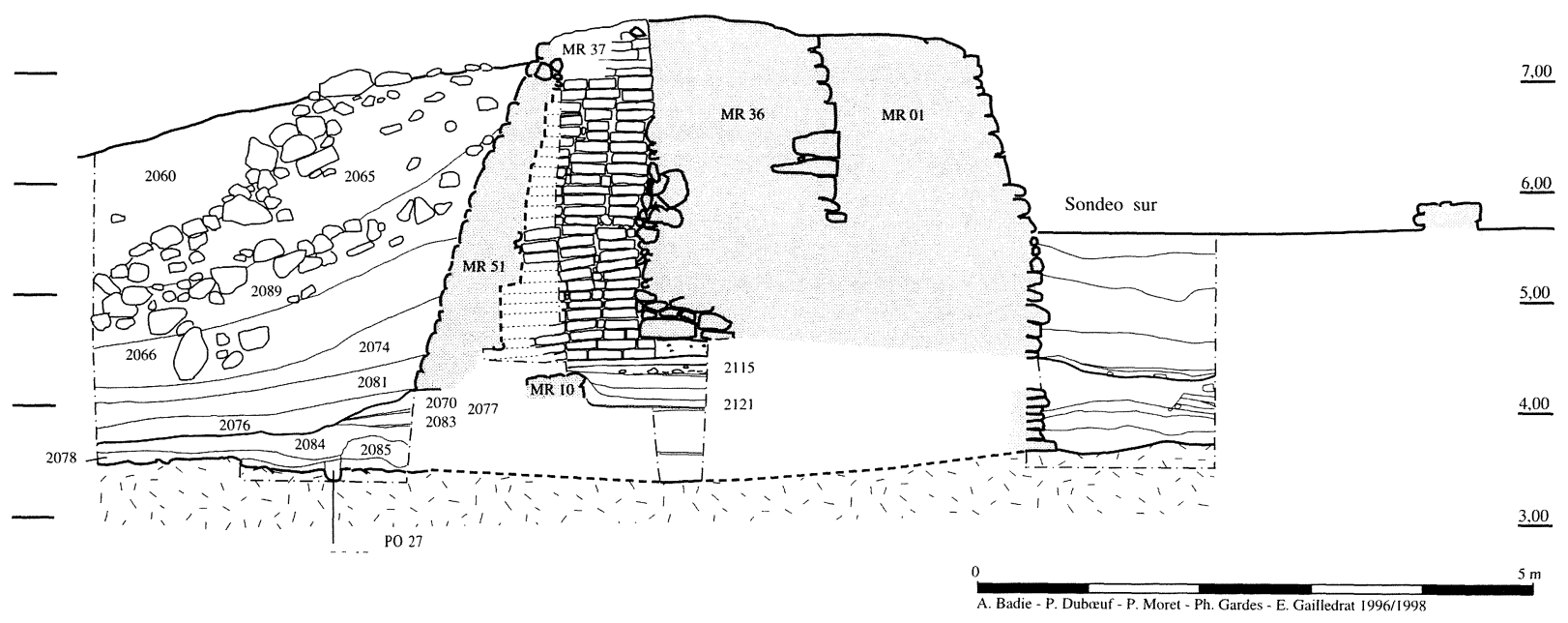

Fig. 5. La Rábita, Guardamar del Segura (Alicante): Perfil C3.

en particular de las UE 2078, 2084, 2085, 2083, 2077 y 2070 entre las que se diferencian claramente dos fases. En parte excavado en el extrato, el agujero de poste PO 27 corresponde a la ocupación más antigua del lugar (Lam. II). Este nivel se halla cubierto por varias capas de relleno (UE 2078, 2084) que contenían un material fechable en la primera mitad del siglo VII. Inmediatamente por encima, un suelo de tierra batida (UE 2083) está relacionado probablemente (a pesar del hiatus de $0,9 \mathrm{~m}$. en el corte estratigráfico) con el muro MR 10, de $0,47 \mathrm{~m}$. de anchura, descubierto en 1998 por debajo de la base de la muralla. El muro MR 10 delimitaba al este un espacio cuyo suelo estaba cubierto por una capa de cal (UE 2121). La vivienda a la que pertenecía MR 10 y la UE 2121 tiene una datación ante quem proporcionada por el material de la UE 2115 que es posterior al arrasamiento de MR $10 \mathrm{y}$ anterior a la construcción de la muralla. Este material, cuyo estudio detallado se halla en curso, contiene fundamentalmente cerámica de barniz rojo datable entre fines del siglo VII e inicios del siglo VI.

3. Los diversos elementos de la murallas se construyen simultáneamente. Pese a su aparente heterogeneidad, la excavación ha demostrado que la muralla había sido concebida y construida de una sola vez, con la excepción de algunos tramos de MR 01 que parecen haber sido reparados o reconstruidos al mismo tiempo que las viviendas de la última fase de ocupación. De hecho, en el paramento de MR 01 son visibles varios cortes indicativos de una

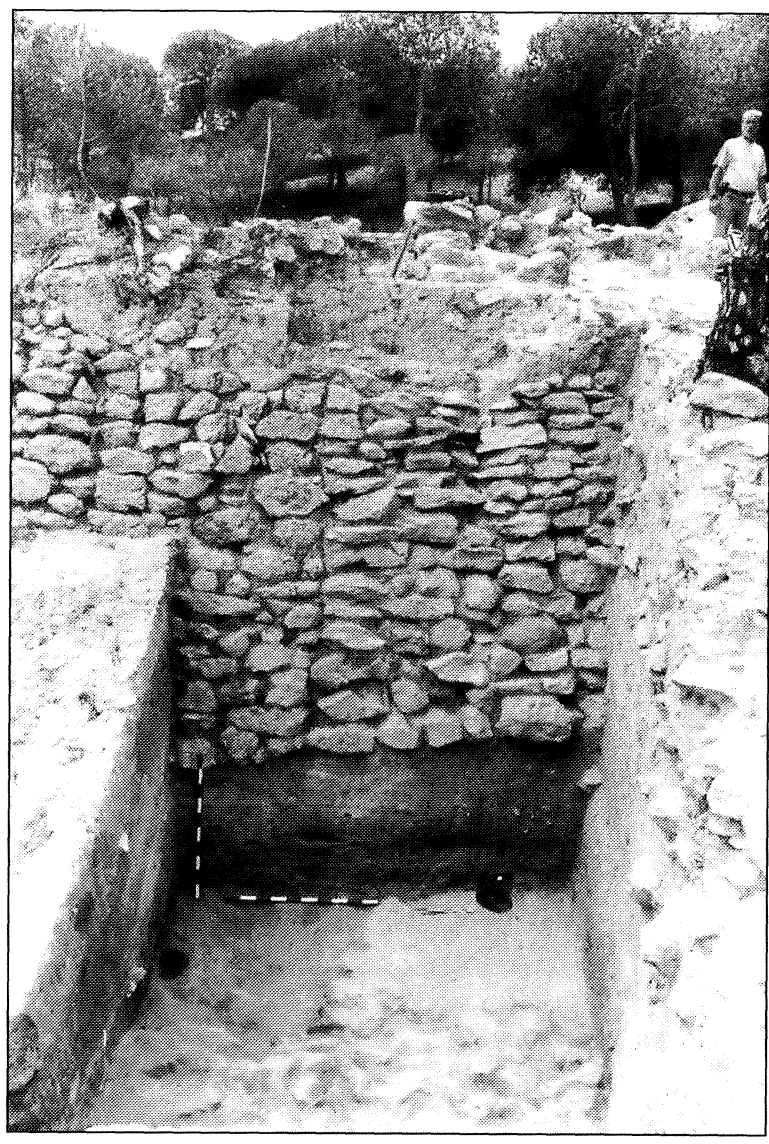

Lám. II. La Rábita, Guardamar del Segura (Alicante): sondeo en la parte exterior de la muralla (se nota la presencia de un hoyo de poste bajo el paramento exterior). 


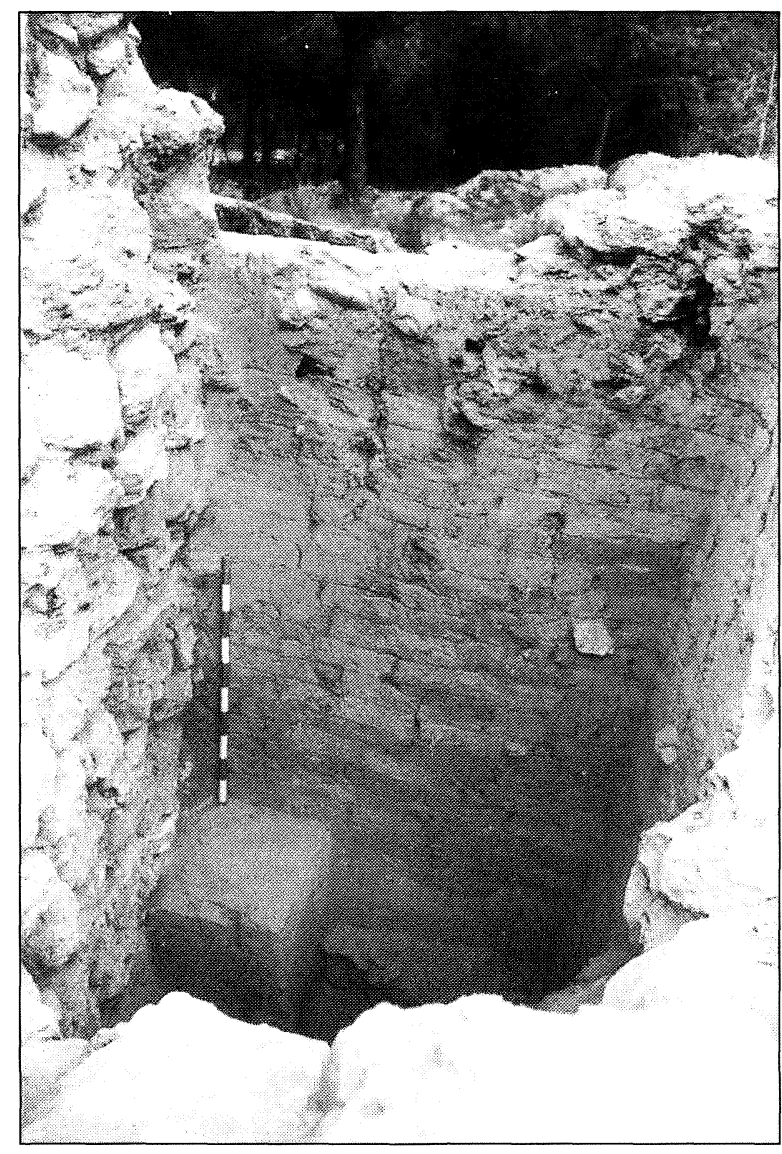

Lám. III. La Rábita, Guardamar del Segura (Alicante): muro de adobe MR 37 del núcleo de la muralla.

técnica de construcción mediante tramos independientes.

4. Tras el abandono del yacimiento, la muralla se arruina progresivamente: primero cae el revestimiento arcilloso (UE 2081), después se derrumban los adobes de las superestructuras (UE 2074, 2066), y finalmente varias hiladas de piedra (UE 2089 y 2065).

5. En época moderna, la arena de las dunas acaba por acumularse contra el talud formado por los derrumbes de la muralla (UE 2060).

La evidencia principal que muestra esta estratigrafía es que la construcción de la muralla pertenece a un episodio tardío de la historia del yacimiento, muy probablemente posterior al final del siglo VII. Las estructuras de hábitat de las fases de ocupación anteriores se extendían más allá de los límites del recinto del siglo VI, y hasta el momento no se conoce fortificación alguna relacionada con esta fase.
La estructura maciza de la muralla, el aparejo tosco y el fuerte talud de sus paramentos, la existencia de paramentos internos, el empleo de adobe para el alzado, todos estos rasgos se encuentran en numerosas construcciones defensivas orientalizantes del sur de la Península Ibérica (Moret, 1996: 299-302 y 314), concretamente en Tejada la Vieja (Escacena del Campo, Huelva), Castillo de Doña Blanca (Puerto de Santa María, Cádiz), Torreparedones (Baena, Córdoba) y Puente Tablas (Jaén), así como también en el Cabezo Pequeño del Estaño, a escasos kilómetros siguiendo el mismo margen del Segura (Fig. 2) (García Menárguez, 1995a). No obstante, la muralla de Guardamar se diferencia de todas éstas por la inclusión de un muro de adobes en el núcleo mismo del basamento. Esta técnica original -no se conocen otros ejemplos en la España prerromana- debe responder sin duda a la necesidad de dar a la construcción un núcleo más firme y más compacto que la amalgama informe de piedras que normalmente rellena el interior del basamento de las murallas.

\subsection{Los datos del hábitat}

\subsubsection{Las diferentes fases de ocupación}

La realización de dos sondeos profundos, uno al exterior y el segundo en el interior del perímetro de la muralla, nos ha permitido establecer la secuencia estratigráfica completa del yacimiento hasta el estrato de base constituido por una capa de arena estéril de color ocre. Se trata, pues, de un hábitat de larga duración cuya fundación tiene lugar entre fines del siglo VIII e inicios del siglo VII a.C. y su abandono en el tercer cuarto del siglo VI a.C.

En el área de excavación nos encontramos con un conjunto de habitaciones adosadas al paramento interno de la muralla a las que se accede desde una calle que, al menos en este sector, discurriría paralela a la misma (Fig. 4). La excavación en extensión ha documentado las dos últimas fases de ocupación del yacimiento; sin embargo, la secuencia completa ha podido registrarse gracias a un sondeo realizado en el extremo sur del área de excavación. Evidentemente, las observaciones efectuadas en esta ocasión sólo son válidas para esta zona, si bien esperamos que puedan ser completadas para poder aplicarlas en un marco más amplio dentro del yacimiento. Con todo, se puede proponer ya una secuencia de cinco fases distintas de ocupación. Estas nos permiten restituir el papel de La Rábita en la facies de la primera Edad del Hierro de la zona, 
que ya se conoce gracias a los cercanos yacimientos de Peña Negra (Crevillente) y Los Saladares (Orihuela).

La fase más antigua (I) comprende un nivel de ocupación (UE 3104) relacionado con un primer muro de bloques irregulares perpendicular al paramento interno de la muralla, cuya identificación permanece todavía bastante imprecisa. Un relleno (UE 3103) se apoya contra esta construcción. Del contexto material descubierto en esta fase, poco abundante, cabe destacar la cerámica fenicia de barniz rojo de cronología bastante antigua, que aporta una datación en torno a finales del siglo VIII a.C.

El terminus ante quem nos viene dado por la fase siguiente (II), mejor definida, que ha sido documentada tanto al interior como al exterior de la muralla, donde aparecen estructuras -aparentemente de habitación-construidas con materiales perecederos, identificadas por una serie de agujeros de poste (Lam. II). Instalados tanto en un caso como en el otro sobre niveles anteriores, estas estructuras coexisten con el muro primitivo, y están en relación con capas (UE 3102) que han dado abundante material arqueológico. Una datación en la primera mitad del siglo VII a.C. parece plausible, a juzgar por la asociación de cerámicas de pasta clara con cerámica fenicia bícroma y de barniz rojo.

La siguiente fase (III) está delimitada claramente por una alteración de los niveles anteriores, así como por el arrasamiento del muro construido en la fase I. Una primera capa de ocupación (UE 3100) está parcialmente recubierta por un relleno (UE 3096b) sobre el cual se extiende un nivel de suelo (UE 3142). El contexto material orientalizante está formado por la asociación de cerámica a mano junto con las primeras producciones a torno aparentemente regionales que se pueden calificar de "Protoibéricas", tanto en cerámica gris como en pasta clara; la cerámica pintada fenicia también está representada. El marco cronológico que aportan estos materiales es excesivamente amplio, si bien permite proponer una datación centrada en los años finales del siglo VII a.C.

Las fases IV y V se identifican por la aparición de las primeras producciones propiamente ibéricas, que coexisten con una abundante cerámica a mano. En cambio, los productos fenicios son cada vez más escasos, representados sólo por ánforas del sur peninsular, salidas de los talleres de Cádiz o Málaga. Los datos obtenidos en las campañas de 1997 y 1998 permiten definir cronológicamente este momento en el siglo VI a.C.

\subsubsection{El último nivel de ocupación, fase $\mathrm{V}$ (550-525 a.C.)}

En primer lugar, es necesario destacar la estrecha relación entre la fortificación y el hábitat, en la medida en que la primera estructura del urbanismo de la fase precedente, como así lo indica en particular la imbricación ya comentada de diversos muros de habitación en el paramento interno de la muralla (Lam. I). Así, una serie de construcciones aparecen adosadas a ésta, formando una manzana alargada (zona 3) delimitada al oeste por una calle (zona 4) que discurre en sentido noroeste-sureste (Fig. 4). La arquitectura de esta fase refleja la utilización de diversas técnicas complementarias.

La primera, y más corriente, consiste en un zócalo de piedra de doble paramento, con una altura media entre 40 y $60 \mathrm{~cm}$., sobre el que se eleva un alzado de adobes. El zócalo se construye con un mampuesto de piedras calizas poco trabajadas, trabado con tierra, y en ocasiones un gran bloque se coloca en las esquinas. El mampuesto es irregular, aunque dispuesto en hiladas que no son del todo rectilíneas.

El alzado está constituido por adobes cuyas dimensiones se constatan tanto en aquéllos encontrados in situ como en los descubiertos en los niveles de colmatación. En este último caso, los adobes aparecen generalmente bien conservados, como demuestra un lienzo de muro caído en el sector B, probablemente el muro de la fachada oeste de la vivienda. De colores variados, del gris al castaño oscuro pasando por el castaño-amarillento, estos adobes presentan un módulo principal de 0,43 x 0,31 x 0,14 m., completado por un semi-módulo similar al documentado en los adobes de la muralla. El análisis de la composición mineralógica demuestra la utilización de arcillas extraídas de las inmediaciones del yacimiento (conteniendo trazos de antropización como pequeños carbones), mezcladas con vegetales y arena de origen eólico. Este dato es interesante para la restitución del paisaje protohistórico, ya que indica que ya en esta época las dunas se situarían en un entorno próximo al yacimiento (8).

La segunda técnica consiste en muros construidos con un macizo de tierra, mostrando a veces una estructura mixta. Se ha documentado en diversas ocasiones (MR 07, MR 24 y MR 23) y parece emplearse preferentemente en muros en tabiques. Estos muros están desprovistos de zócalo de piedra y

(8) Análisis geológico realizado por P. Barrier (IGAL).

T. P., 55, n. ${ }^{\circ} 2,1998$ 
se construyen con un alzado de tierra compacta (o bauge) (9). Algunos guijarros de pequeño o mediano tamaño pueden disponerse en la base con la función, bien de delimitar el trazado del muro en el momento de la construcción, bien de cimentar el muro facilitando que la tierra se aglutine con la piedra. Algunas veces se emplean adobes fragmentados mezclados con la tierra del alzado (MR 24 y MR 23). En otros casos, estas mismas construcciones se pueden completar con jambas de piedra, encontradas caídas en el extremo occidental de los muros MR 07 y MR24.

Este sistema, cuya función es reforzar la estructura de la construcción, denota una realización cuidada. Por desgracia, lo documentado para esta fase es bastante escaso debido a las alteraciones posteriores al abandono del yacimiento, que son también las causantes de la casi desaparición de los muros de la fachada oeste de las viviendas de esta manzana. Estos muros, ademas de verse afectados por la propia dinámica de ruina del yacimiento, también han sido objeto de expolio. Pese a ello, los límites occidentales pueden ser restituidos con total certeza (Fig. 4). Algunos conjuntos arquitectónicos correspondientes al ultimo nivel de ocupación han sido definidos de este modo.

Al sur (sector A), una primera unidad, de la que nos falta el límite meridional, constituye un vasto espacio abierto a la calle. El muro MR 03 no se prolonga hacia el sur. En cambio, en su prolongación ha aparecido una alineación de piedras clavadas verticalmente sobre el suelo, en una longitud de 2 m., que están delimitando una masa de arcilla endurecida. Esta construcción ha podido servir de umbral, y en todo caso materializa el límite entre la calle y el sector A.

Éste parece haber funcionado como espacio abierto, a modo de patio entre dos casas. Ningún elemento de infraestructura doméstica ha sido documentado. Por el contrario, un ancho hogar en cubeta poco profunda aparece en la mitad norte de la estancia (FY 34). Cuatro piedras instaladas en el fondo de la cubeta realizan la función de soporte.

La función de este espacio es difícil de precisar a causa de la casi ausencia de ajuar asociado. La densidad de estructuras, fosas, hogares y elementos construidos hacen pensar en un sector dedicado a alguna actividad artesanal, o al menos a un sector con fines utilitarios. En el extremo meridional de la

(9) El término bauge designa en francés la técnica de construcción en tierra maciza amasada y apilada. A diferencia del tapial, la tierra no se compacta en un encofrado. excavación, la presencia de una capa con abundantes carbones, un numeroso conjunto cerámico y diversos objetos de bronce (puntas de flecha, fíbula) no ayuda a determinar su función concreta.

Los sectores B y C constituyen una sola unidad de habitación, formada por una gran estancia cuadrangular de unos $25 \mathrm{~m}^{2}$ y un espacio más reducido (una decena de $\mathrm{m}^{2}$ ) dividido en dos por un tabique (MR 07). Sobre el suelo de tierra batida de la estancia principal, un hogar rectangular $(0,80 \times 0,90$ m.) está realizado con un simple capa de arcilla cuya superficie aparece rubefactada (FY 22). Su posición, en el centro de la habitación, lo convierte en el elemento en torno al cual se organizaría la vida doméstica. Ningún elemento del tipo banqueta ha sido documentado; sólo un agujero de poste situado en la mitad sur indica la realización de algún arreglo difícil de definir. En cambio, la puerta de entrada desde la calle se ha documentado perfectamente. Se compone de una puerta de una sola hoja cuyo gozne encajaría en una chumacera calzada con piedras, situada en el límite norte del muro MR 06. La mortaja del umbral, constituida por una piedra clavada verticalmente en el suelo, se encuentra en la misma alineación, a casi $1 \mathrm{~m}$. Además, el endurecimiento de la arcilla observado en esta cota revela la existencia de un nivel de circulación entre el interior y el exterior de la estancia.

Dos hogares de forma lenticular y función doméstica (FY 33 y FY 39) se instalaron en la calle, muy próximos a la puerta antes descrita. Así, el espacio exterior se añade a la vivienda para las actividades domésticas, en particular la cocina.

Al lado de esta estancia, la parte norte de la vivienda parece haber tenido una función de almacén. Aquí, los dos pequeños espacios definidos por MR 07 pudieron servir para albergar vasos de almacenamiento, ánforas u otros, pero lo reducido del espacio hace sospechar en la existencia de unas planchas de madera a las que dicho murete serviría de base y sobre las que ya se colocarían los vasos de almacenaje. La escasa elevación de MR 07 es un argumento a favor de esta hipótesis. La ausencia de material, en cambio, no permite confirmar esta idea, pero parece indicar una recuperación casi completa del ajuar en el momento de abandono del hábitat.

El acondicionamiento de los otros sectores es más difícil de precisar, primero por los límites de espacio impuestos a la excavación, y después por las alteraciones más recientes ocasionadas en este sector. En consecuencia, las relaciones entre los diferentes sectores sólo pueden ser restituidas parcialmente. 
El sector F corresponde a un nuevo patio situado entre dos casas. En este reducido espacio descubierto de poco más de $2 \mathrm{~m}$. de ancho, la estratigrafía revela una serie de desechos domésticos indicadores de varias actividades. Un pequeño hogar en cubeta de forma oblonga (FY 32), situado muy cerca del muro MR 24, pertenece a esta última fase.

Este patio registra dos momentos distintos relacionados con la evolución de la construcción. En efecto, en un primer momento el patio presentaba unas dimensiones mayores, con más de 3,5 m. de ancho. En un segundo momento, la casa situada inmediatamente al norte se extiende apropiándose una parte del espacio $(\mathrm{Db})$.

Esta casa (sector D) está formada, en efecto, por dos estancias distintas. Al norte, la más grande de las dos (Da) presenta una banco corrido (BQ 25) a lo largo del muro MR 23. Aunque rota hacia el oeste por una fosa medieval o moderna, al igual que los muros de la fachada oeste, conserva una longitud de $1,20 \mathrm{~m}$. conservado $\times 0,50 \times 0,45 \mathrm{~m}$. Se trata de un banco de tierra sobre basamento de piedra, uniendo el empleo de adobe con tierra compactada: la parte anterior de la elevación está constituida por adobes colocados horizontalmente, mientras que la parte posterior es un relleno de tierra embutida en el espacio libre. Este banco corresponde a un elemento doméstico destinado al reposo.

$\mathrm{Al}$ sur, una pequeña estancia (ancho en torno a $1 \mathrm{~m}$.) se acondiciona en un segundo momento, y parece haber cumplido una función de almacén: en el fondo, y paralelo a la muralla, se construye una banqueta baja (BQ 30). Sobre un basamento de mampuesto, un pavimento de adobes se dispone en todo el ancho de la estancia (diám. 1 x 0,75 x 0,25 m.) utilizando tanto adobes completos como fragmentados. Se trata de un dispositivo destinado a la colocación de productos no identificados. Esta estancia ha sufrido los efectos del fuego, como indica la rubefacción de las estructuras de tierra, en particular del muro MR 28, así como la impronta de un poste de madera en el ángulo sureste.

E1 muro MR 28 presenta una construcción muy cuidada y un estado de conservación excepcional. El alzado de adobes, que conserva en algunas hasta seis hiladas, dobla parcialmente la anchura del zócalo del lado norte formando así un paramento más espeso. Mientras que el zócalo de mampuesto tiene un ancho de $40 \mathrm{~cm}$., el conjunto del muro de la fase $\mathrm{V}$ presenta una anchura de casi $60 \mathrm{~cm}$. Por este lado, los adobes descansan directamente sobre un primer pavimento de tierra batida.
No ha sido encontrado ningún hogar en el interior de esta segunda unidad de habitación, pero también es verdad que la fosa medieval cortó buena parte del suelo de la estancia principal (Da). Ésta es de hecho de dimensiones algo menores que la estancia principal de la primera vivienda (B), con una superficie restituida inferior a $15 \mathrm{~m}^{2}$ que la convierte en una estancia de habitación normal. Estas dimensiones son acordes con la media observada en las estancias del hábitat ibérico antiguo de El Oral (Abad y Sala, 1993: 164-165) o, fuera ya del ámbito regional, en la zona de Cataluña (Belarte, 1997). Por último, el umbral de mampostería descubierto en la prolongación de MR 28 permite la comunicación entre las dos estancias $\mathrm{Da}$ y $\mathrm{Db}$.

El sector E, en el límite norte de la excavación, permanece incompleto. Resulta difícil asegurar si se trata de una unidad independiente o de una habitación perteneciente a la misma vivienda. Un banco bajo o plataforma semicircular (BQ 31) se adosa a la muralla. Está construido en adobes sobre basamento de piedras. La forma oblonga y las dimensiones $(1,60 \mathrm{~m}$. conservadas x 1,40 x $0,20 \mathrm{~m}$.) conducen a su interpretación como una estructura de almacenaje o de una zona de trabajo. Cabe destacar el revestimiento de adobes, constituido por fragmentos de diferentes colores dispuestos en un mosaico irregular.

Parece, pues, que esta manzana adosada a la fortificación consiste en una serie de unidades domésticas de dimensiones medias (unos $27 \mathrm{~m}^{2}$ para la primera vivienda; un mínimo de $18 \mathrm{~m}^{2}$ para la segunda durante la fase más reciente) que alternan con espacios abiertos donde se llevarían a cabo actividades todavía desconocidas dentro del ámbito doméstico.

Las técnicas constructivas, la organización espacial así como la tipología de la infraestructura doméstica revelan una facies indígena, comparable con otros yacimientos ya considerados como ibéricos. El estudio del ajuar correspondiente a esta última fase (Fig. 6 a 8), contrastado con los datos arquitectónicos arriba comentados, confirma la pertenencia cultural y cronológica de esta última fase al período Ibérico antiguo. Los niveles de ocupación correspondientes muestran un ajuar homogéneo desde el punto de vista cronológico; su comparación con el repertorio del cercano poblado de El Oral, de principios del siglo V, nos ofrece elementos de referencia para fijar la datación de esta fase entre la mitad y el tercer cuarto del siglo VI a.C.

En este ajuar se encuentra un borde de ánfora

T. P., 55, n. $^{\circ} 2,1998$ 


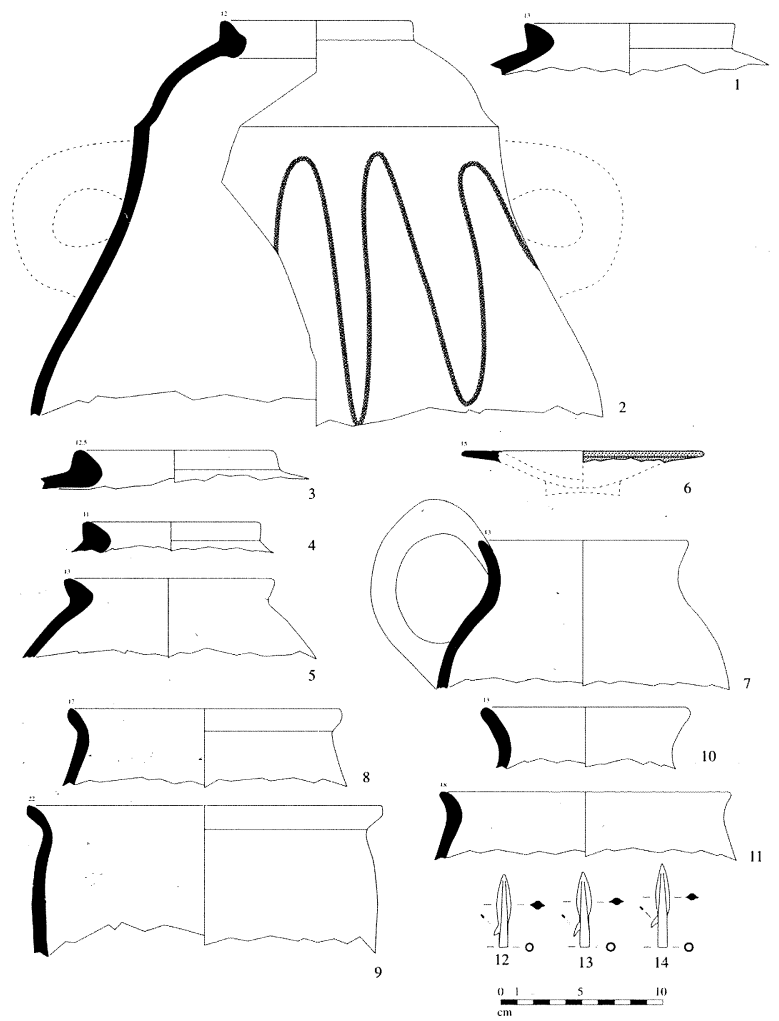

Fig. 6. La Rábita, Guardamar del Segura (Alicante): material de la fase V (550-525 a.C): ánfora fenicia de occidente (1-2), ánfora ibérica (3-5), barniz rojo (6), cerámica de cocina a torno (8-9), cerámica común a torno (7 y 9-10), bronce (12-14).

fenicia producida en la región de Málaga (Fig. 6, $\mathrm{n}^{\circ} 1$ ). Otro ejemplar, producido en la zona de Cádiz, presenta una decoración raspada no documentada hasta ahora (Fig. 6, $n^{\circ}$ 2). Se trata de un ejemplar del tipo Ramón 10.1.2.1, cuya cronología abarca desde el segundo cuarto del siglo VII a mediados del siglo VI a.C. Tres bordes de ánforas ibéricas, dos de fábrica probablemente regional (Fig. 6, $n^{\circ} 3$ y 4), la segunda procedente de una taller meridional (Fig. $6, n^{\circ} 5$ ), evocan formas próximas a los tipos documentados en la primera mitad del siglo $\mathrm{V}$ en El Oral (Abad y Sala, 1993: 206-207).

La cerámica de barniz rojo tartésica (orientalizante) es poco abundante. Está representada únicamente por un borde de plato de ala horizontal de pequeño tamaño (Fig. $6, n^{\circ} 6$ ) cuya forma, derivada de prototipos bien conocidos en barniz rojo fenicio todavía producidos a principios del siglo VI, es similar a un tipo de plato que a partir del siglo $\mathrm{V}$ a.C. se fabrica ampliamente en producción pintada (tipo Mata-Bonet 3812).
La cerámica gris está bien representada, con diversas formas abiertas que se encuentran en términos generales en el repertorio de El Oral, pero que derivan de tipos más antiguos producidos en el mundo fenicio o tartésico. Así, se documentan platos carenados de borde exvasado (Fig. $7, \mathrm{n}^{\circ} 1$ y 2 ). Los platos profundos de perfil troncocónico, labio redondeado o biselado al interior, están también presentes (Fig. 7, ${ }^{\circ} 4$ y 5 ). Las formas cerradas son más raras, a pesar de que se encuentra algun tipo de urna sin cuello y borde divergente, de cuerpo bicónico (tipo Peña Negra B10a del que deriva el tipo U2 de El Oral).

Las producciones ibéricas pintadas son particularmente abundantes, con un repertorio en el que predominan las formas cerradas: jarra pithoide (Fig. $\left.7, \mathrm{n}^{\circ} 8\right)$, jarras de cuello corto divergente y borde subtriangular (Fig. 7, ${ }^{\circ}$ 9) o de cuello divergente y borde horizontal (Fig. 7, $\mathrm{n}^{\circ} 12$ y 13). Las bases son cóncavas (Fig. 7, n ${ }^{\circ} 10$ ), mientras que un borde exvasado perteneciente a una urna desprovista de cuello se aproxima a ciertas formas a mano fabri-
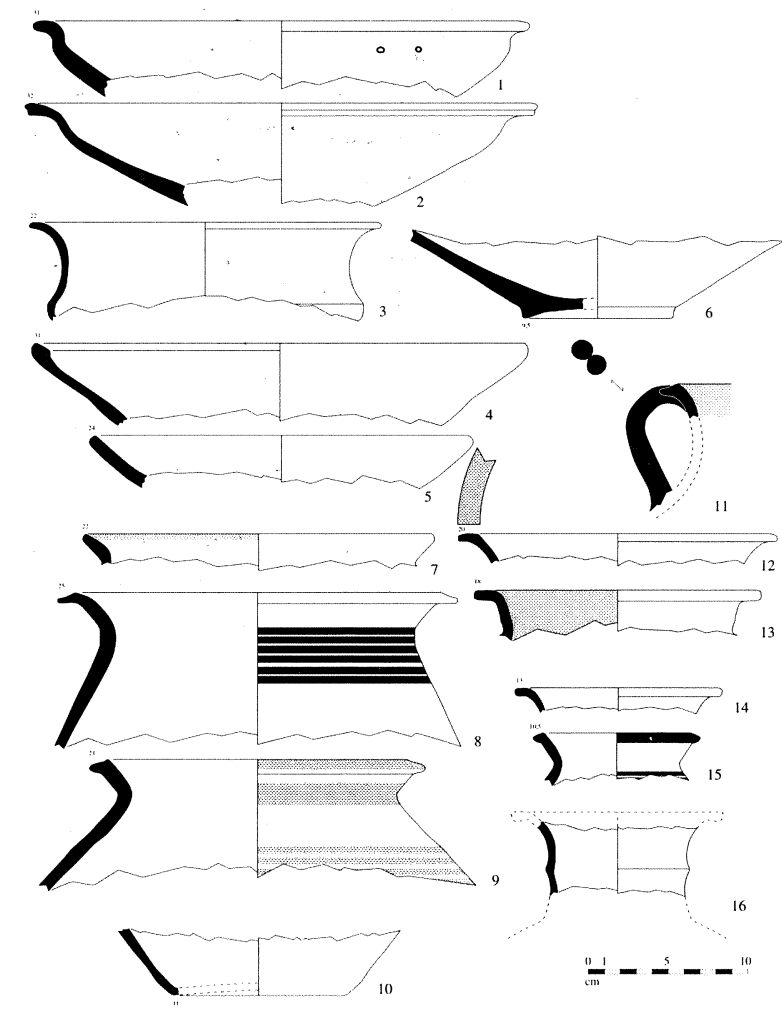

Fig. 7. La Rábita, Guardamar del Segura (Alicante): material de la fase V (550-525 a.C): cerámica gris (1-6), cerámica ibérica pintada (7-16). 
cadas todavía en esta época (Fig. $7, \mathrm{n}^{\circ} 7$ ). Por último, se documenta la urna de cuello cilíndrico con un baquetón del tipo "Toya", fechable en la segunda mitad del siglo VI a.C. (Fig. 7, ${ }^{\circ} 16$ ). Un borde incompleto parece pertenecer a una jarra de cuello cóncavo y asa bífida que arranca del borde (Fig. 7, $\left.\mathrm{n}^{\circ} 11\right)$; esta forma es bastante extraña y podría proceder del repertorio mediterráneo.

Algunos fragmentos pertenecen a ciertas producciones a torno no pintadas de origen mal definido, con una pasta diferente a la de las series pintadas ibéricas. Las formas documentadas son también originales: se trata, en primer lugar, de una urna sin cuello y borde divergente (Fig. $6, n^{\circ} 10 \mathrm{y}$ 11) que recuerda las ollas a mano características de la zona (comparar con Fig. 8, $\mathrm{n}^{\circ} 1$ ). Es posible ver aquí el indicio de un repertorio de transición, en la medida en que estas formas desaparecen rápidamente, como se ve en El Oral donde ya no existen. Un borde similar, pero perteneciente a una urna con asa (Fig. $6, n^{\circ} 7$ ) evoca asimismo un repertorio de transición con aquel característico del Ibérico antiguo. Esta forma recuerda la de las ollas de cocina a mano producidas en el mundo fenicio entre la mitad del siglo VIII y el primer cuarto del siglo VI a.C. (tipo Schubart-Maass XXI, 3) (Schubart y Maass-Lindemann, 1984). Ausente de la vajilla de cocina ibérica ya a principios del siglo $\mathrm{V}$, esta forma se relaciona por tanto con una facies más antigua de mediados del siglo VI a.C.

La cerámica de cocina a torno de grueso desgrasante está documentada por dos ejemplares de olla de embocadura ancha (Fig. 6, n 8 y 9), un tipo ausente en el repertorio de cocina de El Oral. Podemos ver, pues, un tipo formal más antiguo, en gran medida derivado de modelos de urnas a mano de perfil en $\mathrm{S}$.

Las cerámicas a mano están muy representadas en este nivel. Este hecho debe ser destacado porque nos ofrece un argumento importante para distinguir la facies de El Oral de ésta de Guardamar, a pesar de las similitudes ya mencionadas en cuanto a las produccions ibéricas. Los vasos a mano representan casi la mitad del total de hallazgos, mientras que este tipo de productos han desaparecido por completo a fines del siglo VI. Hay que señalar, además, que las formas existentes se inscriben en el repertorio tradicional que evoluciona sin interrupción desde el tránsito del Bronce Final a la Primera Edad del Hierro, como muestran claramente las excavaciones en Peña Negra (González Prats, 1983). Se encuentran fundamentalmente ollas sin cuello de borde divergente (Fig. $8, \mathrm{n}^{\circ} 1$ ) o sub-cilíndrico, así como ollas de perfil convexo y borde simple convergente (Fig. 8, $n^{\circ} 6$ a 8 ), a menudo provistas de mamelones. También están presentes algunas formas abiertas, cuenco de perfil convexo y mamelones (Fig.8, $\mathrm{n}^{\circ} 13$ ), cuenco de perfil troncocónico (Fig. $8, \mathrm{n}^{\circ} 16$ y 17 ), y escudillas de perfil convexo y borde horizontal (Fig. 8, $\mathrm{n}^{\circ}$ 14) que recuerdan una forma intermedia entre el repertorio fenicio (Schubart-Maass VIII, 2c) y el propiamente ibérico (Mata-Bonet 3812c) (Mata y Bonet, 1992). Finalmente, algunos cubiletes de perfil sinuoso completan este repertorio (Fig. 8, ${ }^{\circ} 9$ ).

El ajuar metálico comprende un conjunto de tres puntas de flecha de arpón del tipo Macalón, en su variante más frecuente en la Península Ibérica, es decir, la $11^{\mathrm{TM}}$ de la tipología de J. Ramón (1983). Estos ejemplares de bronce derivados de prototipos mediterráneos orientales presentan un cubo tubular así como una marcada nervadura central convexa (Fig. 6, $\mathrm{n}^{\circ} 12$ a 14). La cronología de estas piezas concuerda con las observaciones realizadas para el

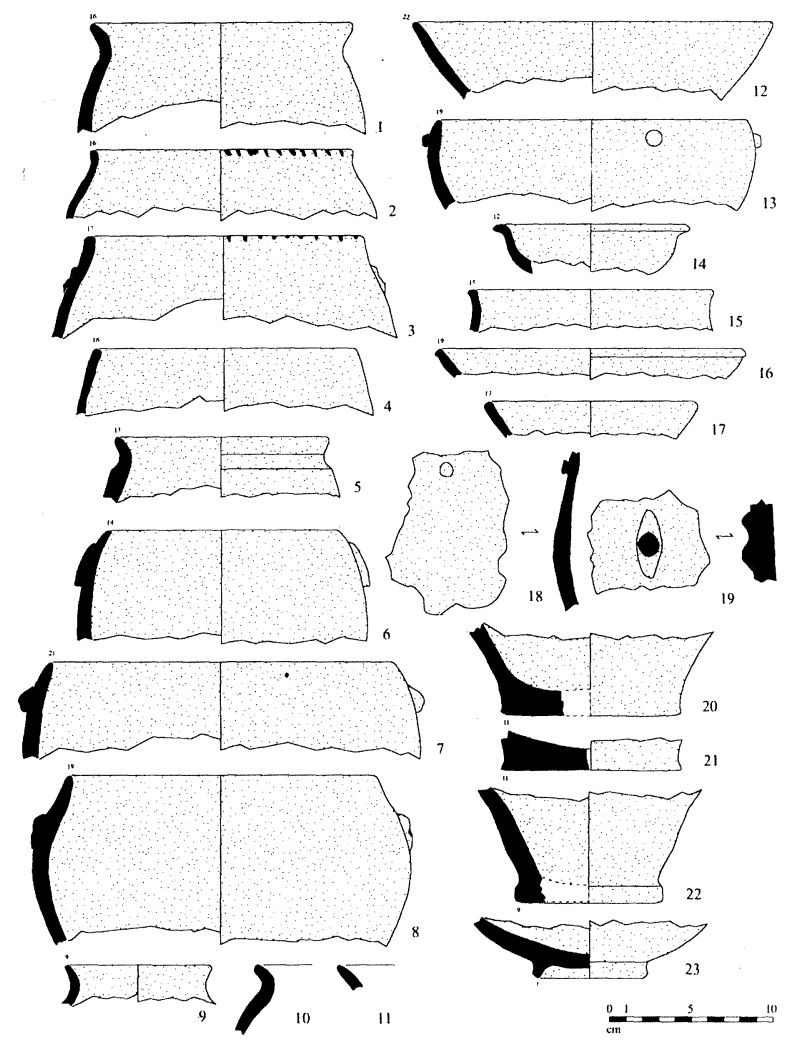

Fig. 8. La Rábita, Guardamar del Segura (Alicante): material de la fase V (550-525 a.C): cerámica a mano. 
ajuar cerámico, y dan una datación durante el siglo VI a.C., más bien hacia la mitad de este siglo (Quesada, 1989, 1997).

\subsubsection{La fase IV (600-550 a.C.)}

El sistema de casas adosadas a la muralla se inscribe en un registro urbanístico bien conocido en el mundo orientalizante e ibérico. Cabe señalar que una parte de sus líneas directrices responde a la puesta en práctica de un verdadero esquema preestablecido, documentado en la fase IV. Las observaciones realizadas en el sondeo estratigráfico han sido completadas en 1998 por la excavación de los niveles de ocupación correspondientes.

El sondeo meridional ha mostrado, además, que esta fase es contemporánea a la edificación de la muralla. El paramento interno, edificado en sucesivos tramos a lo largo de las dos últimas fases del hábitat, se articula de manera compleja con las estructuras de habitación, bien incluidas en un último resfuerzo del paramento (así los muros MR 04 y 05), bien adosadas a MR 01, éste edificado de manera casi simultánea al resto de la muralla en torno al 600 a.C. En la parte meridional de la excavación, una construcción se adosa a la muralla, mostrando que en este punto el refuerzo interno MR 01 fue realizado ya en un momento antiguo.

Asistimos, por tanto, a una reorganización general del espacio habitado que se ve circunscrito de este modo en un sistema defensivo cuyas características han sido descritas más arriba. Frente a las dificultades técnicas deducibles de la técnica constructiva empleada, la disposición cuidadosa de la articulación hábitat/muralla demuestra una cierta planificación del espacio.

La fase IV muestra un cierto número de cambios arquitectónicos, tanto a nivel del plano como de las técnicas constructivas.

El sector meridional, espacio abierto durante la última fase, en este momento está ocupado por una vivienda de varias estancias (sectores G-H-I). La fachada oeste se delimita por un muro con una puerta que da acceso a la calle. Esta puerta de simple batiente (PR 47) se compone de un umbral de piedras trabadas con tierra asociado a una chumacera, dando acceso a la estancia $\mathrm{H}$. La arquitectura de los muros de la fachada oeste (MR 44) y sur (MR 38) es particularmente cuidada. MR 38 consiste en un zócalo de piedras trabadas con tierra con un alzado de adobes del que se conservan las dos primeras hiladas. El zócalo presenta un aparejo bien cuida- do: en la base una hilada de nivelación hecha con bloques irregulares. Sobre ella, el zócalo propiamente dicho, construido con un mampuesto regular dispuesto en cuatro hiladas, con una altura de unos $50 \mathrm{~cm}$. Un relleno de unos $25 \mathrm{~cm}$. de espesor se dipone contra la base del muro cubriendo de esta manera la hilada de nivelación. Esta construcción en el suelo mismo, con una base rellenada, se caracteriza por la calidad de su realización. Una cama de preparación de tierra se coloca sobre el zócalo con el objeto de recibir la primera hilada de adobes. Éstos presentan unas dimensiones regulares de 42$44 \times 33 \times 9 \mathrm{~cm}$., completadas por un semi-módulo de $18-19 \times 42-44 \times 9 \mathrm{~cm}$., otra vez totalmente comparable a algunos adobes utilizados en la construcción de la muralla. Las juntas verticales de tierra presentan un ancho de $1-2 \mathrm{~cm}$. Las horizontales, en cambio, se componen también de tierra arcillosa, pero presentan mortero de cal dispuesto en finas lechadas en contacto con la hilada de adobes. El mismo mortero blanco también se ha encontrado de manera discontinua en la superficie del revestimiento de tierra que recubría la pared interna de MR 38.

La puerta (PR 47), con un ancho de $0,75 \mathrm{~m}$., está flaqueada por dos jambas hechas con piedras recibidas con tierra: la primera corresponde al muro MR 03, todavía en alto durante la fase $\mathrm{V}$, mientras que la segunda es arrasada al igual que el resto de la edificación en torno a mediados del siglo VI a.C. Esta construcción está dividida en varias estancias por un primer tabique este-oeste (MR 45) que delimita al sur una pequeña estancia rectangular (sector I). En esta última, un banco de adobes sobre zócalo de piedra (BQ 61) discurre a lo largo del muro oeste (MR 44).

El tabique MR 45 tiene una puerta que da acceso a la parte norte de la habitación. Esta puerta (PR 49) se presenta una vez más acondicionada con un umbral -éste con adobe-flanqueado al este por una jamba en piedra cuya función de refuerzo de la construcción parece evidente.

La parte norte de la vivienda está dividida a su vez en dos (sectores $\mathrm{H} \mathrm{e} \mathrm{I}$ ) por un nuevo tabique norte-sur (MR 46) que forma un ángulo recto con MR 45. Este muro presenta una técnica diferente, aquella ya mencionada de construcciones macizas de tierra sin zócalo. El límite norte de este muro está mal definido, pero no parece prolongarse hasta MR 02 permitiendo así la comunicación directa de una estancia con otra.

En el extremo meridional de la excavación, MR 38 presenta una vuelta adosada a la muralla, y 
paralela a ésta. Lo exiguo de la superficie no permite extender la excavación; no obstante, es posible imaginar que este espacio se une a la misma unidad arquitectónica que las estancias $\mathrm{H}$, I y G que ocupan ya una superficie de más de $26 \mathrm{~m}^{2}$. Ningún elemento de infraestructura doméstica se ha documentado en el último nivel de suelo de esta vivienda. Por el contrario, un hogar se encuentra en la calle, en las cercanías de la puerta, con trazas de haber sido utilizado por los habitantes de esta casa.

Inmediatamente al norte, le sigue una segunda casa. Sus límites corresponden a los de los sectores B y C. Pocas cosas distinguen en este punto la fase IV de la fase $\mathrm{V}$, si no fuera por la ausencia del tabique MR 07. En lo que concierne a MR 04 y MR 05, la excavación muestra que el alzado de adobes de estos dos muros fue arrasado a fines de la fase IV: durante la fase $\mathrm{V}$ el nivel de arrasamiento sirve de base para los zócalos de nuevas construcciones.

Se documentan algunos hogares circulares, constituidos por una capa de arcilla extendida sobre un encachado de guijarros o de fragmentos cerámicos. Un primer hogar, con varias refacciones, se localiza en la parte sureste de la estancia B. Un segundo, de factura similar, se encuentra en el ángulo noreste de la estancia C. Más que un lugar de almacenaje, parece tratarse de una habitación dedicada a cocina complementaria de la estancia principal.

Pese a que el plano de la vivienda permanece, cabe resaltar algunos cambios importantes en las técnicas constructivas, en la medida en que los vestigios del alzado de adobes del primer estadio de MR 05 presentan la técnica ya descrita del empleo de mortero de cal para las juntas horizontales.

Una vez más, la presencia de un hogar lenticular situado en la calle, a poca distancia de la puerta, testifica la anexión de una parte del espacio exterior para las actividades domésticas, en particular la cocina.

Durante la fase IV, los sectores F y Db constituyen un solo y único espacio, que parece corresponder a un vacío dejado entre dos construcciones. Una serie de capas de desechos domésticos, alternadas con empedrados de guijarros, se asocian a un hogar construido sobre una capa de gravas y fragmentos cerámicos.

La parte norte de la excavación se presenta de manera diferente. La existencia del muro MR 28 durante este período no está totalmente clara. Su alzado de adobe visible, perfectamente conservado a causa de una rubefacción parcial, constituye en todo caso una refacción tardía (fase V) sobre un zó- calo ya existente. Es en el momento de esta refacción cuando se realiza también la prolongación del muro. No es del todo cierto que en su estado inicial fuera el de un muro de vivienda propiamente dicha. En efecto, los sectores $\mathrm{D}$ y $\mathrm{E}$ se caracterizan por la presencia de capas cenicientas relacionadas con elementos diversos, como hogares y estructuras de refuerzo de piedra dispuestas en la parte norte. El muro MR 23, edificado en una fase antigua (como demuestra su imbricación en el paramento de la muralla), es derribado en un momento que corresponde al final de la fase IV. En este momento, un simple murete retiene la tierra del lado norte, compensando la pendiente natural que presenta el terreno en este punto. Este elemento se situa a algunas decenas de centímetros cerca del trazado inicial del muro. En la fase $\mathrm{V}$ es cuando éste se reconstruye, retomando un trazado materializado en el suelo y en el paramento de la muralla. Los sectores D y E son espacios abiertos durante la fase IV, quizá dedicados a actividades artesanales. Se puede, no obstante, imaginar la presencia de estructuras de tipo voladizos, en particular en el nivel del sector D. Las excavaciones futuras deberán confirmar o desestimar tal hipótesis.

En lo que concierne a la datación de esta fase IV, el ajuar en curso de estudio permite proponer una datación en la primera mitad del siglo VI a.C. El material recogido en 1997 en el sondeo estratigráfico, completado por el descubierto en los niveles de ocupación excavados en 1998, muestra en efecto una homogeneidad cronológica: en el sondeo meridional, en la UE 3096a se asocia un borde de jarra de pasta clara con un fragmento de cuerpo de un vaso cerrado de tipo propiamente ibérico. Se encuentra asimismo una copa en cerámica bruñida, así como un fondo de cerámica a torno indeterminada, quizá un mortero mediterráneo. La aparición en este nivel de los primeros testimonios cerámicos clasificables como "ibéricos" nos conduce a buscar una datación en la primera mitad del siglo VI. La presencia de una fíbula de bronce confirma esta impresión: se trata de una fíbula de doble resorte bilateral corto de 8 vueltas, con un sentido de torsión. El arco es curvo, de sección rectangular. La mortaja de media caña debía recibir la aguja (desaparecida) que arrancaría de una espira mediana del resorte. El pie, fragmentado, podría ser del tipo recto o elevado. Este ejemplar sería próximo al tipo "Acebuchal" de Cuadrado, datado en la primera mitad del siglo VI (Cuadrado, 1963). Este tipo conoce una gran difusión, y se encuentra en la misma época al norte de los Pirineos (tipo Mohen 2121).(Mohen, 1980).

T. P., 55, n. ${ }^{\circ} 2,1998$ 
Por tanto, es posible proponer como terminus ante quem la mitad de este mismo siglo. Cabe destacar que una forma cercana, provista de un pie recto, se encuentra en la necrópolis de Mas de Mussols (Tortosa), hacia el 575-525 a.C. (Maluquer de Motes, 1984, Fig. 19, n 6 ).

Las dataciones obtenidas en el hábitat concuerdan perfectamente con las de la muralla. Con los límites fijados en la primera mitad del siglo VI, la facies que se perfila, caracterizada por la presencia de las primeras producciones artesanales estrictamente ibéricas, debe entenderse como un momento a caballo entre los períodos Protoibérico e Ibérico Antiguo.

\section{CONCLUSIÓN}

¿Qué facies podemos definir finalmente para el yacimiento de La Rabita de Guardamar? La respuesta no debería ser única, teniendo en cuenta que los niveles más explorados pertenecen en lo esencial a los períodos Protoibérico/Ibérico Antiguo. Existe en primer lugar una facies orientalizante, pero para la cual se plantea el problema de la identidad de sus habitantes, fenicios, tartesios, o mixto. La relevancia de las importaciones procedentes del mundo semita de Occidente, fundamentalmente andaluz, ya ha sido destacada. A ello cabe añadir la presencia de ciertos objetos orientales, traidos por el negocio fenicio de bienes de prestigio: huevos de avestruz y vasos de alabastro. A este ambiente orientalizante hay que añadir los elementos arquitectónicos reutilizados en los muros de la Rábita cuyo estudio se halla en curso; su cronología es todavía imprecisa, pero se encuentra, en particular con la cornisa de gola egipcia, un elemento del repertorio arquitectónico fenicio y púnico que ha sido frecuentemente utilizado por los iberos.

Dos puntos nos parecen claros: por un lado, que nos encontramos ante un desembarcadero de importancia, lugar de intercambios particularmente favorable en la desembocadura del río Segura, y por otro, que este lugar ha funcionado durante largo tiempo hasta el inicio de la época ibérica. ¿Qué sentido cabe otorgar a la primera instalación documentada? ¿Qué sentido cabe dar asimismo a los niveles del siglo VII o a las estructuras de barro registradas a partir de varios agujeros de poste contemporáneas de otros tipos de construcciones más sólidas, en un contexto marcado por la abundante presencia de material fenicio? Todavía es demasiado pronto para responder a estas cuestiones. De hecho, la riqueza del yacimiento que no ha conocido un arrasamiento posterior corresponde a su larga (y probablemente compleja) historia: todas las fases comprendidas entre el período Orientalizante hasta el Ibérico Antiguo están representadas, y dejan su rastro tanto en la arquitectura como en el material cerámicos.

\section{BIBLIOGRAFÍA}

Arqueología en Alicante 1976-1986. Diputación Provincial de Alicante. Alicante.

ABAD CASAL, L. (1992): "Terracotas ibéricas del Castillo de Guardamar". Estudios de arqueología ibérica y romana. Homenaje a Enrique Pla Ballester. Trabajos Varios del S.I.P., 89. Valencia: 225-238.

Abad Casal, L. y Sala Sellés, F. (1993): El poblado ibérico de El Oral (San Fulgencio, Alicante). Trabajos Varios del S.I.P., 90. Valencia.

Arteaga, O. y Serna, M. R. (1975): "Los Saladares-71". Noticiario Arqueológico Hispánico, Arqueología, 3: 7-140.

- (1980): "Las primeras fases del poblado de Los Saladares (Orihuela-Alicante)". Ampurias, 41-42: 65-137.

Azuar Ruiz, R. (1989): La Rábita califal de Las Dunas de Guardamar (Alicante). Cerámica, Epigrafía, Fauna, Malacofauna. Diputación Provincial de Alicante. Alicante.

- (1991): "La Rábita de Guardamar y el paleoambiente del Bajo Segura (Alicante) en el siglo X". Boletín de Arqueología Medieval, 5: 135-150.

BARCEló Torres, C. (1985): “Almodóvar, una población de la Cora de Tudmir sepultada en La Rábita de Guardamar del Segura". Saitabi, 35: 59-71.

Belarte Franco, M.C. (1997): Arquitectura domèstica i estructura social a la Catalunya protohistòrica. Arqueo Mediterrània, 1. Barcelona.

CUADRADO, E. (1963): "Precedentes y prototipos de la fíbula anular hispánica”. Trabajos de Prehistoria, VII: 7-61.

De Chazelles, C.A. (1997): Les maisons en terre de la Gaule Méridionale. Monographies Instrumentum, 2. Montagnac.

Estévez, A. y PinA, J.A. (1991): “Dunas, playas y marjales del Cuaternario en el litoral sur de la provincia de Alicante". En A. Escarré, J. Martín y E. Sera: Estudios sobre el medio ambiente y la biocenosis en los arenales costeros de la provincia de Alicante. Instituto de Estudios Juan Gil-Albert. Alicante: 15-26.

FERnÁNDEZ GutiérReZ, J.C. (1986): "Paleolíneas de costa del Sudeste español desde el Plioceno al Cuaternario reciente". Historia de Cartagena, III. Murcia: 15-38.

FERnÁNDEZ JuRAdo, J. (1988-1989): Tartessos y Huelva. Huelva Arqueológica, X-XI.

Figueras Pacheco, F. (1957): Historia de Guardamar del

T. P., 55, n. $^{\circ} 2,1998$ 
Segura en la Edad Antigua. Instituto de Estudios Alicantinos. Alicante.

García MenÁrguez, A. (1989): "Sobre la localización del topónimo Almodóvar en la desembocadura del Segura". Sharq al-Andalus, 6: 149-157.

- (1993): "El Castillo de Guardamar. Nuevos datos sobre el poblamiento ibérico en la desembocadura del río Segura". Alebus, 2-3: 68-96.

- (1995a): "El Cabezo Pequeño del Estaño, Guardamar del Segura. Un poblado protohistórico en el tramo final del río Segura". Symposium internacional Sociedad y cultura púnica en España (Cartagena, 1990): 269280. Cartagena.

- (1995b): "Avances sobre las excavaciones en yacimientos con fases del Hierro Antiguo en el tramo final del río Segura (Guardamar del Segura, Alicante)". XXII Congreso Nacional de Arqueología (Vigo, 1993): 225-229. Vigo.

GonZÁlEz PraTs, A. (1979): Excavaciones en el yacimiento protohistórico de La Peña Negra, Crevillente (Alicante) (la y 2 a campañas). Excavaciones Arqueológicas en España, 99. Madrid.

- (1982): "La Peña Negra IV, Excavaciones en el sector VII de la ciudad orientalizante 1980-1981". Noticiario Arqueológico Hispánico, Arqueología, 13: 305-418.

- (1983): Estudio arqueológico del poblamiento antiguo de la Sierra de Crevillente. Anejo I de Lucentum. Alicante.

- (1985): “La Peña Negra, II-III. Campañas de 1978 y 1979”. Noticiario Arqueológico Hispánico, Arqueología, 21: 7-155.

- (1989): "Últimas aportaciones de las excavaciones realizadas en la Peña Negra (1983-1987) al Bronce Final y Hierro Antiguo del Sudeste y País Valenciano". XIX Congreso Nacional de Arqueología (Castellón de La Plana, 1987). I: 467-475. Zaragoza.

- (1990a): Nueva luz sobre la protohistoria del Sudeste. Universidad de Alicante. Alicante.

- (1990b): "La factoría fenicia de Guardamar". Azarbe, Suplemento Cultural de la Revista de Moros y Cristianos de Guardamar del Segura. 5 julio 1990.

- (1991): "La presencia fenicia en el Levante peninsular y su influencia en las comunidades indígenas". I-IV Jornadas de Arqueología Fenicia-Púnica (Ibiza, 19861989): 109-118. Ibiza.

- (1992): "El proceso de formación de los pueblos ibéricos en el Levante y Sudeste de la Península ibérica”. En Paleoetnología de la Península Ibérica. Complutum, 23: $137-150$.

- (1993a): "Ausgrabungen in der frühgeschichtlichen Siedlung von Herna (La Peña Negra/Crevillente, Prov. Alicante)". Madrider Mitteilungen, 34: 142-152.

- (1993b): "Quince años de excavaciones en la ciudad protohistórica de Herna (La Peña Negra, Crevillente, Alicante)". Saguntum-PLAV, 26: 181-188.

GonZÁlez Prats, A. y García MenÁrguez, A. (1997): "La co- lonización fenicia en el tramo final del Río Segura (Guardamar del Segura, Alicante)". Alquilibla, 3: 87-102.

MaAss-Lindemann, G. (1985): "Vasos fenicios de los siglos VIII-VI en España, Su procedencia y posición dentro del mundo fenicio occidental". Aula Orientalis, 3 (1): 227-239.

MALUQUER DE MOTES, J. (1984): La necrópolis protoibérica de 'Mas de Mussols', Tortosa (Tarragona). Barcelona.

MATA, C. y Bonet, H. (1992): "La cerámica ibérica: ensayo de tipología". Estudios de arqueología ibérica y romana. Homenaje a Enrique Pla Ballester. Trabajos Varios del S.I.P., 89. Valencia: 117-173.

Mohen, J.P. (1980): L'Âge du Fer en Aquitaine du VIIIème au IIIème siècle av.J.-C. Mémoires de la Société Préhistorique Française, 14. Paris.

Moret, P. (1996): Les fortifications ibériques, de la fin de l'âge du bronze à la conquête romaine. Collection de la Casa de Velázquez, 56. Madrid.

Moret, P.; Puigcerver, A.; Roulllard, P.; SÁnChez, M.J. y Sillières, P. (1995): "The Fortified Settlement of La Picola (Santa Pola, Alicante) and the Greek Influence in South-east Spain". En B. Cunliffe and S. Keay (eds.): Social Complexity and the Development of Towns in Iberia. Proceedings of the British Academy, 86. Londres: 109-125.

Moret, P.; Roulllard, P.; SÁnchez, M.J. y Sillières, P. (1996): "La Picola (Santa Pola): un asentamiento fortificado de los siglos V y IV A. C. en el litoral alicantino". XXIII Congreso Nacional de Arqueología (Elche, 1995), I: 401-406. Zaragoza.

NiEMEYeR, H.G. (1995): "Phoenician Toscanos as a Settlement Model? Its Urbanistic Character in the Context of Phoenician Expansion and Iberian Acculturation". En B. Cunliffe and S. Keay (eds.): Social Complexity and the Development of Towns in Iberia. Proceedings of the British Academy, 86. Londres: 67-88.

QuESADA, F. (1989): "La utilización del arco y las flechas en la cultura ibérica". Trabajos de Prehistoria, 46: 161-201.

- (1997): El armamento ibérico. Estudio tipológico, geográfico, funcional, social y simbólico de las armas en la cultura Ibérica. Monographies Instrumentum, 3. Montagnac.

RAMÓN, J. (1983): "Puntas de flechas de bronce feniciopúnicas halladas en Ibiza: algunos materiales inéditos". En Homenaje al Profesor Martín Almagro Basch II. Ministerio de Cultura. Madrid: 309-323.

Schubart, H. (1976): "Westphönizische Teller". Rivista di Studi Fenici, IV, 2: 179-196.

Schubart, H. y MaAss-Lindemann, G. (1984): "Toscanos. El asentamiento fenicio occidental en la desembocadura del río de Vélez, Excavaciones de 1971". Noticiario Arqueológico Hispánico, Arqueología, 18: 41-205.

Schubart, H.; Niemeyer, H.G. y Pellicer, M. (1969): Toscanos. La factoría paleopúnica en la desembocadura del río de Vélez. Excavaciones de 1964. Excavaciones Arqueológicas en España, 66. Madrid.

T. P., 55, n. ${ }^{\circ} 2,1998$ 